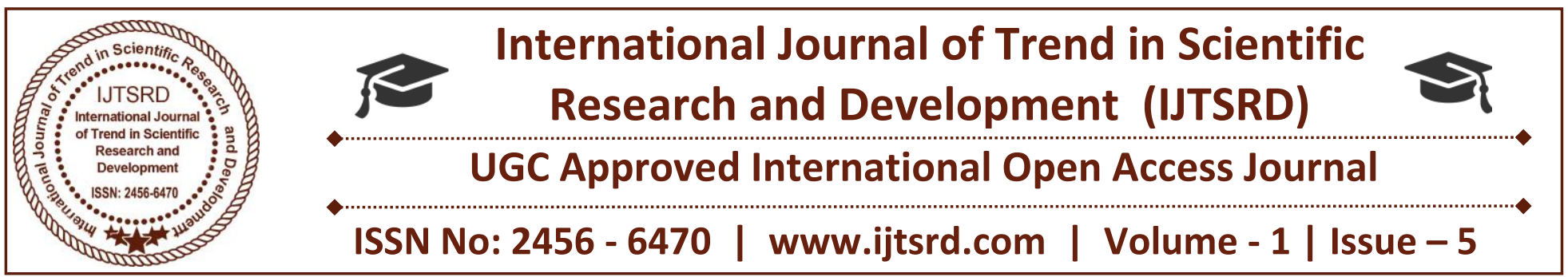

\title{
Language through Literature through Language
}

\author{
Vineet Kaul
}

Scholar, DA-IICT (Dhirubhai Ambani Institute of Information, Communication \& Technology) University Gandhinagar, Gujarat, India

\section{ABSTRACT}

This paper enumerates how the sound empirical footings have strengthened the symbiotic relationship between literature and language. Based on reductive interpretation many teachers regard literature as inappropriate to the classroom of language, but the fact however remains that literature and language both are indivisible and their roles are not contradictory but complementary to each other. In the last decade or so the interest in literature as one of the most valuable language teaching resources available has revived incredibly. Many language teachers believe that literary texts make language acquisition more usefocused instead of form-focused. Language class becomes exciting and reciprocating with impulsiveness and interest.

Literature is constituted by language and it represents one of the most recurrent uses of language. This paper also discusses the reasons for the demise and resurrection of literature as an input for language classes and the benefits language learners can derive from the inclusion of literature and also examine how literature has its own complex role. To mediate changes in pedagogic practice it is the responsibility of language teachers to increase the effectiveness of language teaching for the exploitation and exploration of the symbiotic relationship, Sure we are, if this relationship is harnessed with sedulous attention it would lay a red carpet for a long way bringing high level of efficiency and synergy.

Keywords - Language, literature, relationship, interrelation, symbiotic

\section{INTRODUCTION}

For last three decades interminable debates are going on between literary critics and linguists in academic circles as to whether they should integrate linguistic methods derived from literature. In this unyielding dispute, the claims and denials on both sides have been voiced with great force and passion. This is entirely justified with almost moral indignation. Parallel to this, the status of English has undergone a sea change after the colonial era ended. The unprecedented growth and remarkable advances in ICT and emergence of globalization have changed priorities and languages considered vital attributes of national identity. On one hand, language constitutes literature and literature in turn represents one of the most frequent uses of language. Relationship between literature and language is symbiotic and therefore should be further explored and exploited to enhance effective teaching and learning. Traditional methods should be reviewed in order to pave way for an innovation that would create room for further strengthening relationship between demanding literature and language.

Languages do not only serve as means of communication, they also function as the custodian of their users' cultures and a tool in education Literature exposes students to complex themes and unexpected areas of language use in holistic development. Many people criticize literature as a mere play of imagination without any practical importance. But, in fact, they themselves do not fully understand what literature is? In England, literature is not only seen as sublimation of human thought, passion, feelings concerning issues which are of universal interest but 
also introduces the students to great minds and new forms of experience and also as means of contact with these great minds Paffard (1978). Literature is produced in many countries, in many languages but literature does not know the boundary of nation or race. The literary language is always loaded with metaphorical expressions, rhetorical devices, symbols, hyperbole, etc., to express the writer's views effectively. Literature components may be challenging point in language classes but since they both work in tandem they can offer skills to any leaner in writing, reading and speaking. Literature is the foundation of language learning and cultural transmission from generation to generation.

Many language gurus have generated an interactive discussion as to where, when, why and how literature should be incorporated in language curriculum. Obviously language teachers are using literature for language / cultural enrichment, authentic material and personal involvement. It is argued by many that since there is no dichotomy between father and son so there is no visible demarcation. Hence, the all aspects of literature are as complements .Sociolinguistic opulence is another topnotch function of literature. From one social group to another, the use of language changes and people speak differently in different social contexts. In other words literature provides a wide range of language spectrums like regional dialects, jargons, sociolects and idiolects etc. Hence, incorporating literature into language teaching will empower sociolinguistic aspects and elicit strong, positive reactions. Therefore, it sounds absurd to study Literature without language at the centre stage or to study language without Literature playing a prominent role. Literature is rooted in language and language gets life through Literature and that is why they become inseparable. Literature is constituted by language and it represents one of the most recurrent uses of language. While selecting literary texts, it is of utmost importance for the teacher to choose books relevant to real-life experience and cultural background of students. Literature will teach us four language skills like reading, listening, writing, speaking and these skills are not to be taught in isolation but in integrated way. The approach towards comprehension of literary work should adopt a dynamic and student centered. Students are ready to do collaborative work after comprehending a literary selection at the literal and inferential level. This means they share their evaluations of the work. Oral reading, dramatization, improvisation, role-playing, pandomiming, re-enactment, discussion, and group activities may centre on a work of literature.

It is true that literature plays a noteworthy role in the English programmes but there are number of practical problems which hinder while teaching English through literature. First and foremost there are very few pedagogically- designed relevant materials which can be used by teachers in a language class-rooms. Then there is lack of preparation in literature teaching, structural complexity, and lack of conformity to standard grammatical rules, and remote control perspective. There is no synergy between two classes of teachers since every one of them is on their own, Language teachers should have the same identical training designed and they should be competent enough to teach literature, Language teachers should also create learning environment, fostering learners 'Positive attitude towards language. Last but not least, clear cut objective defining the role of literature is absent. Ironically many teachers without having background and training include literature failing expectations of literary competence. As Obediat(1997:32) states to acquire competency in English students have to learn English linguistic system for communication, affluent use of idiomatic language, speak clearly, precisely and become analytical learner.

In sum, literature provides students with an incomparably rich source of authentic material over a wide range of registers. If students can gain access to this material by developing literary competence, then they can effectively internalize the language at a high level (Elliot 1990:198). Especially, for students with verbal / linguistic intelligence, the language teacher's using literature in a foreign language class serves for creating a highly motivating, amusing and lively lesson. Literature is not only a tool for developing the written and oral skills of the students in the target language but also is a window opening into the culture of the target language, building up a cultural competence in students

\section{Language: High Point of Literature}

Language is the backbone for effective communication and acts as best when conveyed in lucid and comprehensive manner. Related to the fact that everyone speaks their own language is the fact that spoken languages change inexorably. The colonial masters bequeathed us English language as a legacy and there are number of arguments against the 
use of literature in language teaching. The place of literature in language teaching has relentlessly been portrayed differently by the fact that the canon of 'great' literature has changed dramatically over the centuries under the influence of cultural and critical tastes. Many EFL teachers have discarded literature arguing that it is only work of art, beyond proficiency and used as filler. To incorporate literature as a resource for teaching languages, different prospective have exposed the advantages and disadvantages. This topic has been argued back and forth innumerable times with no clear resolution. Hotly contested debates have gone through remarkable significant revolution on the role of literature in language because of increasing attention to the schism between language and literature studies. The rapport between literature and English language teaching was a controversial issue and Mckay (1882) lamented its minimal contribution towards the teaching of grammar. Besides, literature contributed nothing to help students to achieve academic and occupational goals. This pointed out towards two fundamental issues which are not always differentiated: the relation between linguistics and literary criticism, on the one hand, and the relation between language and literature, on the other. Although these two issues are closely interrelated, they can profitably be treated separately. Resultantly many teachers think literature as a separate subject and that has nothing to do with language learning. At a stage, even literature was excluded from language teaching programme owing to many reasons including structural complexity and its excellent use of language. As literature reflects cultural perspective which is difficult to conceptualize by foreign language students, therefore, it is uninteresting for them. One of the most influential figures in the field of literature, Maley (2001), mentions the lack of empirical research in support of the facilitative role of literature as the main reason for the negative view.

On the other hand some scholars believe that literature enhances linguistic knowledge of the learner (Povey, 1967) Pugh (1989) argues that literature is a rich source of meaningful input especially in EFL settings.. A couple of years ago Chatman and Levin foretold that the reconciliation is positively looming large in the air and we are nearing the destination. With the emergence of communicative language teaching in the 1980s, a revival in using literary texts as part of the EFL curriculum took place and both became indivisible until today. The literature was once again in to language instruction but without domination but a resource of language teaching (Lazar 2005). Later, literature became a reservoir for language exploration into stylistic and discourse analysis.

No literature comes to life without language and no language can survive without literature. Literature cannot emerge in the absence of language and language cannot survive in the absence of literature. Literature-in-English and the English language are tools in the hand of each other. While language is a tool by which literature establishes an existence, literature serves as a tool through which language propagates itself. The relationship between language and literature is an interdependent one; literature does not and cannot exist independent of language because language is the conveyor of literature. Language classrooms are seen reverberating with literary texts to teach language and stylistics and discourse analysis surely give us the space to study literature as codes of language. An understanding of the nature and structure of language would enable us to appreciate a literary work much better because language and thoughts are the raw materials of literature. Literary writers use language in their works. Literature is as central to language learning as management vocabulary and cloze tests. Literature can be used to teach language, for instance, drama and poetry can be used for the teaching of speech while rose can be used to teach summary, comprehension and human communication. Literature supplies many linguistic opportunities to the language learner and allows the teacher to design activities that are "based on material capable of stimulating greater interest and involvement" than many other non-literary, informative texts (Carterand Long 1991: 3).

Every language is itself a collective art of expression and the medium of literature as marble, bronze and clay are the materials of the sculptor Language and literature are inseparable. Literature is great because of its universality and doesn't exist in vacuum .The inclusion of literature in language teaching and learning can bring a fresh breeze into the dry and mechanical task of language learning and teaching. Reading literature involves language learning and countries like India where native language is not English, must expand language awareness as English is a vehicle for any writings. Learners must be exposed to unmodified language and skills which I considered by experts biggest idiosyncrasies. However, literature has successfully maneuvered to 
occupy its deserving place but cannot exist without language. Basically language and literature are two sides of the same coin and inseparable component of humanities. Literature is an important embodiment of language and whatever type of genre, means language is the basic raw material which pulverizes literature. There is no sharp demarcation between language and literature because literature presupposes language and enriches cultural, social and aesthetic values.

Once up on a time English was spoken in medieval England but today it has become global lingua-franca. New media have brought tsunami transformation and polycentericity of its norms. There has been a traditional language/ literature divide and many language educators think it is succinctly and forcefully inflicted upon us. They vehemently reject the study of English literature as a "luxury "and an "exorbitant gewgaw". But researchers have responded to those objections logically and established the importance of using literary texts. They advocate that literature being heart of English gives students exposure to meaningful contexts full of descriptive language and interesting characters. But if you have a close look literature and language enjoy a symbiotic relationship and literature without reference of language is inconceivable. It was, therefore, suggested that the relationship should be explored and exploited so that learners will have high level of proficiency for better results. Literature is rooted in language and language gets life through Literature. So Literature and language are closely interconnected and this relationship is well harnessed in the teaching and learning..Literature is a legitimate and valuable resource for language teaching.

They are reluctant to incorporate literature in syllabus and language pedagogy. This anachronisms made it a contentious issue and a hot debate started among language educators emphasizing the need for a change Nevertheless, despite lingering reservations, in recent years, the teaching of literature in language has widely heralded comeback with lock, stock and barrel. Systematic integration of the two is started in numerous subsequent studies. It is now the responsibility of language teachers to mediate changes in pedagogic practice so as to increase the effectiveness of language teaching."

\section{Symbiotic Relationship between Language and Literature}

Literature and language are not only intertwined but also viewed as heterogeneous interrelated entities in vital live in relationship. It is inconceivable to discuss literature without reference to language. Literature is rooted in language and language gets life through Literature. The upsurge of interest between language and literature is gaining momentum among language educators but in absence of pedagogically-designed appropriate materials and a lack of preparation in the area of literature teaching, the results need to still improve further. Debates re-affirm that literature provides learners with individual lexical or syntactic items; syntax and discourse functions of sentences, Good literature will help integrate innovative skills, dichotomies and build a linguistic component prescribing grammar and vocabulary. Teachers need to adopt student-centered approach towards comprehension of literary work as the technological landscape continues to evolve; ideas related through literature, other modes of artistic expression and language are part of that which is being researched through the Digital Humanities. Myriad of reasons have been advanced by scholars expressing pedagogical need to embed literature in to larger canvas of teaching if teachers care about their students and their profession. Teachers of literature are offered valuable advice to choose most appropriate texts, analyse them stylistically, and use relevant task-based follow-up activities In short, literature provides language learners richness and stimulating variety with authentic material over a wide range of registers. Literature is a legitimate and valuable resource for language teaching.

\section{Learning Language through literature}

Language and literature are two paramount components in English studies for linguistic competence. Good literature not only improves language learning but also inspires motivation, which results in broader understanding. The use of literary language is not mandatorily compulsory as the ordinary language. Because of its appeal to the learner's imagination and emotions, literature provides motivation for language learning.. Literature provides learners with authentic models for the norms of language use. Literature assists learners in developing their overall language awareness and knowledge about language. The study of literature helps develop the learner's interpretive and analytical skills (e.g. skills of inference) which can be applied to other language-related activities. Literature represents language "at its best" and thus provides an ideal model for language learning.. Literature provides 
learners with insights into the norms and cultural values embodied in the language.

Reading literature develops subtle vocabulary usage and complex syntax. The other contributions of literature are the motivational and experimental factors, tolerance for cultural differences and promotion of creativity. Further, literature enlarges students" vision and fosters critical thinking. Another benefit refers to the natural and meaningful use of language.

Malay (1989) has distinguished between two purposes for literature teaching. The first one is the study of literature and the second one the use of literature as a resource of language learning. Perhaps one emphasizes the 'special status of literature as one of the many uses of language.

The study of literature educates the "whole person" in a way that more functional approaches to language teaching do Our object is to teach language through literature and not literature per se. Comparing literary and "non-literary" texts allows the learner to move from the known to the unknown: in this way literature is made more accessible to him/her. 11. Linking the study of literary texts to creative language activities (such as rewriting endings to stories, role playing, rewriting a narrative from a different point of view or in a different genre) makes the text more accessible to the learner and removes some of the intimidating mystique that often surrounds literature. Learners cannot develop literary competence without an adequate competence in language. Integration of language and literature helps compensate for any inadequacies in the learner's linguistic competence. Developing the learner's sensitivity to how language is used in a literary text (e.g. through elementary stylistic analysis) provides

Literature is like a mirror through which the temporal dynamics of language is better known. It is imperative that we become "content sensitive" while learning and teaching.

\section{Conclusion}

Literature is a new material in teaching and learning communicative competence of the language. In the literature-based classroom, literature can be the primary material of teaching the target language, providing authentic and real contexts of communicative situations. It also provides the pleasure of learning a new language with and through interesting stories. Students can extend their knowledge and experience of the world by reading literature. The language teacher should encourage students to read literature for their own meanings and experiences instead of being forced to accept the teacher's perception of the text literature provided examples of effective and appropriate usage of the language for the students to learn. Literature also shows students new ways to view the world around them by constructing meaning from the text.

\section{REFERENCES}

1) Carter, R. \& Long, M. (1991) Teaching Literature. Essex \& New York: Longman UK Group

2) Elliot, R. 1990. "Encouraging reader-response to literature in ESL situations" in ELT Journal. Vol 44, No. 3, p.p:191-198

3) Lazar, J. (2005). Literature and language teaching: A guide for teachers and trainers. Cambridge: Cambridge University Press

4) Malay (1989) : 32 years of nationhood

5) Maley, A. (2001). Literature in the Language Classroom. In R. Carter and D.Nunan (Eds.). The Cambridge Guide to TESOL (pp. 180-185). Cambridge: Cambridge University Press.

6) Obediat, M. 1997. "Language vs. Literature in English Departments in the Arab World" in English Teaching Forum.

7) Povey, J. F. (1967). Literature in TESOL Programs: The Language and the culture. TESOL Quarterly, 1, 40-46

8) Pugh, S. (1989). Literature, culture, and ESL: A natural convergence. Journal of Reading, 32, 320329.

9) Paffard, M. (1978). Thinking about English. England: A Member of the Pentos Group. 